\title{
Synchronization New 3D Chaotic System Using Brain Emotional Learning Based Intelligent Controller
}

\author{
Masoud Taleb Ziabari \\ Faculty of Engineering, Computer Engineering Group, Mehr Aeen University, Bandar Anzali, Iran \\ Email: m.t.ziabari@gmail.com \\ Ali Reza Sahab \\ Faculty of Engineering, Electrical Engineering Group, Islamic Azad University, Lahijan Branch, Iran \\ Email: sahab@liau.ac.ir \\ Seyedeh Negin Seyed Fakhari \\ Department of Electrical \& Computer Science, KadousInstiute of Higher Education,Rasht, Iran \\ Email: n_s_fakhari@yahoo.com
}

\begin{abstract}
One of the most important phenomena of some systems is chaos which is caused by nonlinear dynamics. In this paper, the new 3 dimensional chaotic system is firstly investigated and then utilizing an intelligent controller which based on brain emotional learning (BELBIC), this new chaotic system is synchronized. The BELBIC consists of reward signal which accept positive values. Improper selection of the parameters causes an improper behavior which may cause serious problems such as instability of system. It is needed to optimize these parameters. Genetic Algorithm (GA), Cuckoo Optimization Algorithm (COA), Particle Swarm Optimization Algorithm (PSO) and Imperialist Competitive Algorithm (ICA) are used to compute the optimal parameters for the reward signal of BELBIC. These algorithms can select appropriate and optimal values for the parameters. These minimize the Cost Function, so the optimal values for the parameters will be founded. Selected cost function is defined to minimizing the least square errors. Cost function enforce the system errors to decay to zero rapidly. Numerical simulation results are presented to show the effectiveness of the proposed method.
\end{abstract}

Index Terms - New 3D Chaotic System, Synchronization, BELBIC, Genetic Algorithm, Cuckoo Optimization Algorithm, Particle Swarm Optimization Algorithm, Imperialist Competitive Algorithm, Cost Function

\section{INTRODUCTION}

Chaos synchronization, an important topic in nonlinear science, has been developed and studied extensively in the last few years due to its potential application to physics, chemical reactor, biomedical and secure communications. Generally the two chaotic systems in synchronization are called drive system and response system, respectively. The idea of synchronization is to use the output of the drive system to control the response system and make the output of the response system follow the output of the drive system. Chaos synchronization has attracted a great deal of attention ever since Pecora and Carroll [1] established a chaos synchronization scheme for two identical chaotic systems with different initial conditions. Many methods for chaos synchronization have been proposed, such as, Robust Control [2], the sliding method control [3], linear and nonlinear feedback control [4], function projective [5,6], adaptive control [7], active control [8], backstepping control [9], generalized backsteppig method control [10] and so on. But many above-mentioned methods can only applied some given chaotic system, some methods will produce the singularity problem in synchronizing the chaotic system and most of the methods in the literatures need more than one variable information of the master system.

In parallel with industrial and technological improvement, control systems and their control methods have become sophisticated. Control of new systems using previous old methods has become difficult. Further, considering human brain patterns and abilities in order to control and solve problems has resulted in emergence of new intelligent controlling methods which utilizes human brain operation patterns which are mentioned in following. Brain Emotional Learning Based Intelligent Controller (BELBIC) was introduced for the first time by Lucas in 2004 [11]. Brain Emotional Learning Based Intelligent Controller (BELBIC) is an example of bioinspired control methods which is based on limbic system of mammalian brain. This controller is based on emotional behaviors in biological systems. Emotion is an emergent behavior in biological systems for fast decision making in complex environments. The advantages of this behavior cannot be neglected in creature survival [12]. During the past few years, the BELBIC has been used in control devices for several industrial applications. The BELBIC has been successfully employed for making decisions and controlling linear systems and nonlinear systems such as, Brain Emotional Learning Intelligent Controller (BELBIC) for the control of two benchmark nonlinear plants was applied in [13]. In [14], a problem of 
speed tracking of permanent magnet stepper motor has been discussed based on the static PID and newly type of intelligent control which mimics the emotional learning in limbic system of mammalians. Also BELBIC was used to control of Locally Linear Neuro-Fuzzy Model (LOLIMOT) of Washing Machine [15]. BELBIC was applied to a Switched Reluctance Motor (SRM) to tackle the speed and position control problem in [16]. Furthermore, BELBIC was applied for real time positioning of laboratorial overhead traveling crane in [17]. In [18], BELBIC was applied to electrically heated micro-heat exchanger, which was a nonlinear plant. In [19], BELBIC via robust adaptive method is introduced to stabilize uncertain nonlinear systems. Also an intelligent adaptive approach for aerospace launch vehicle control is presented in [20]. Furthermore, designing of PID and BELBIC controllers in path tracking and controlling problem is studied in [21] and finally an intelligent autopilot control design for a 2Dimensional helicopter model is studied in [22].

In this work, utilizing BELBIC model introduced in $[21,22]$, we will design an intelligent controller for synchronization of two new 3D chaotic systems [23]. Simulation results depicts that this proposed controller can synchronize these chaotic systems.

The rest of the paper is organized as follows: In Section 2, the Brain Emotional Learning Based Intelligent Controller (BELBIC) is described. In Section 3 , the new 3D chaotic system is described. In Section 4, synchronization between two new 3D chaotic systems by BELBIC. In section 5, BELBIC is optimized by Evolutionary Algorithms. In section 6, Represents simulation results. Finally, in section 7, Provides conclusion of this work.

\section{BRAIN LEARNING BASED INTELLIGENT CONTROLLER (BELBIC)}

In this method, emotional factors like excitement and anxiety are the roots of learning. Here, the roots of anxiety are assumed as some stimulants and the control system should react in the way that reduces the system anxiety that is caused by these stimulants. The Brain Emotional Learning (BEL) is divided into two parts, very roughly corresponding to the amygdala and the orbitofrontal cortex, respectively. The amygdaloid part receives inputs from the thalamus and from cortical areas, while the orbital part receives inputs from the cortical areas and the amygdala only. The system also receives reinforcing (REW) signal. The emotional learning model in amygdala and orbitofrontal corex is illustrated in Fig.1.

BELBIC has some input sensors that can be chosen by designer. Each input sensor has two different states that can be described as.

$A_{i}=s_{i} v_{i}$

$$
O_{i}=s_{i} w_{i}
$$

In which $s$, is the input sensor and $v, w$ are two states that are depended on input sensor. Index $i$ represents the $i^{T h}$ sensor and its related states. These two will be updated by following equations $[21,22]$.

$$
\begin{array}{r}
\Delta v_{i}=\alpha s_{i} \max \left(0, \text { rew }-\sum A_{i}\right) \\
\Delta w_{i}=\beta s_{i}\left(\text { rew }-\sum A_{i}-\sum O_{i}-\max \left(s_{i}\right)\right)
\end{array}
$$

In which $\alpha, \beta$ are training coefficients and rew is reward signal. Amygdala acts as an actuator and orbitofrontal corex acts as a preventer. Therefore the control signal of BELBIC is.

$$
u=\sum A_{i}-\sum O_{i}
$$

This paper uses the continuous form of BELBIC. In continuous form the BELBIC states are updated by following equations.

$$
\begin{gathered}
\dot{v}_{l}=\alpha s_{i}\left(\text { rew }-A_{i}\right) \\
\dot{w}_{l}=\beta s_{i}\left(r e w+s_{i}+O_{i}-A_{i}\right)
\end{gathered}
$$

A BELBIC controller has to be designed for synchronization two chaotic systems. For traction force sensory inputs considered.

$$
s_{i}=e_{i}
$$

$e_{i}$ is error between master system and slave system. The structure of the control system is illustrated in Fig.2.

Reward signal will be obtained reward function. This function has a great role in BELBIC. Designer must define a reward function that has its maximum values in the most desired regions. In this work, the reward function is chosen as a linear function of system error.

$$
\operatorname{Rew}_{i}=k_{1 i} e_{i}+k_{2 i}
$$

$k_{1 i}$ and $k_{2 i}$ are positive parameters of reward function. The reward function for this BELBIC controller is as Fig.3.

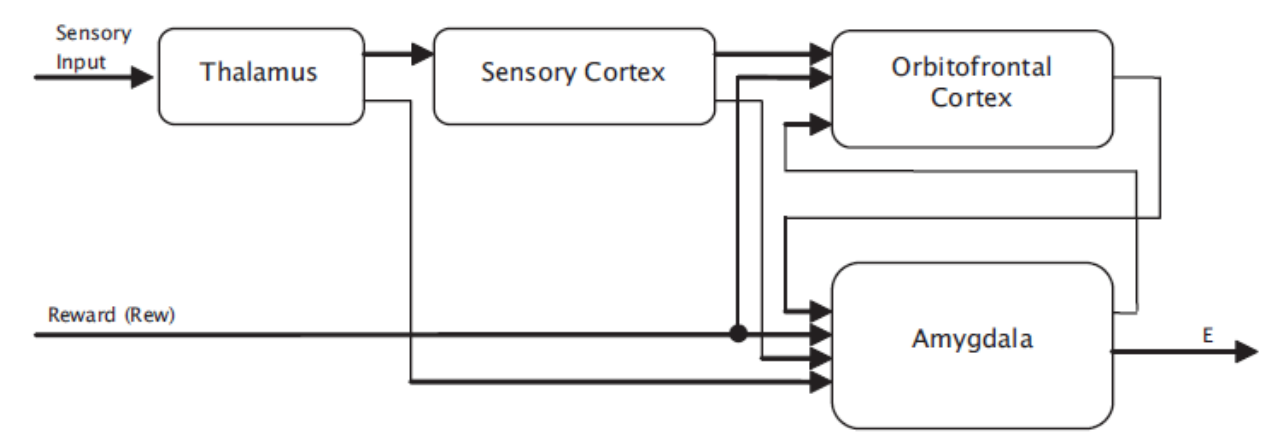

Fig. 1. Scheme of BELBIC structure [11] 


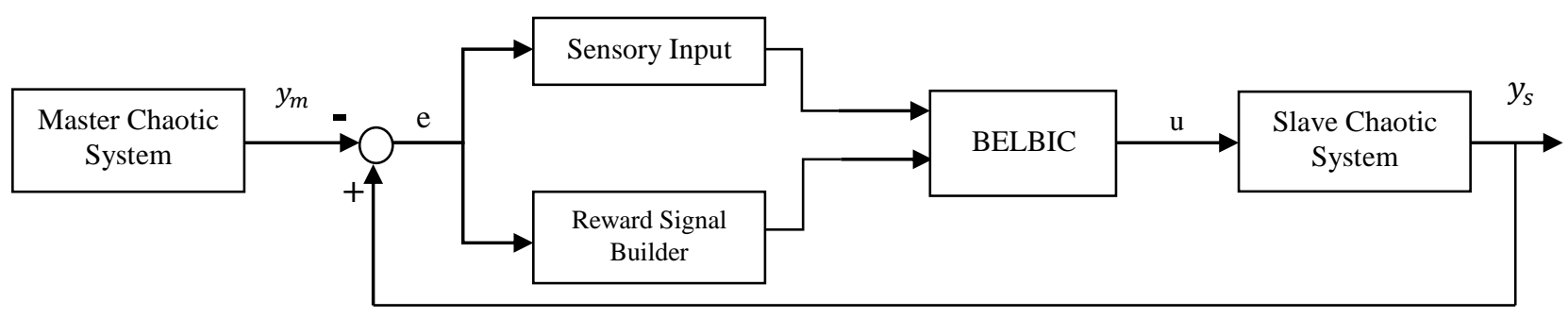

Fig. 2. Control system configuration using BELBIC

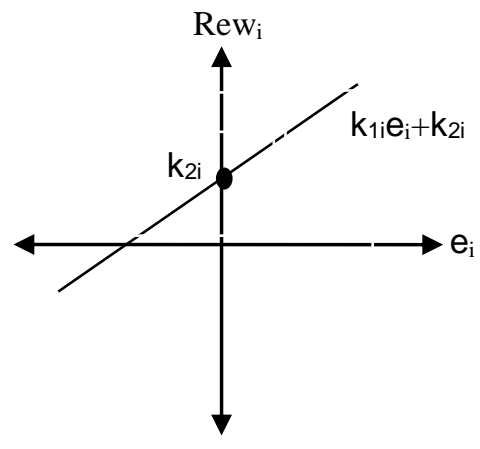

Fig. 3 Reward Function

\section{SYSTEM DESCRIPTION}

Recently, Chunlai $\mathrm{Li}$ and et al generated the 3D autonomous chaotic system with two quadratic crossproduct terms and a square term [23]. The system is described by:

$$
\begin{aligned}
\dot{x} & =-a x+f y z \\
\dot{y} & =c y-d x z \\
\dot{z} & =-b z+h y^{2}
\end{aligned}
$$

Here $x, y, z$ are the state variables and $a, b, c, d, f, h$ are the positive constant parameters. When $a=16, b=$ $5, c=10, d=6, f=0.5, h=18$, system (7) is chaotic witn the Lyapunov exponents $L_{1}=1.86, L_{2}=0, L_{3}=$ -17.73 . The corresponding phase portraits are depicted in Fig.4 and state trajectory of system (7) is displayed in Fig.5.

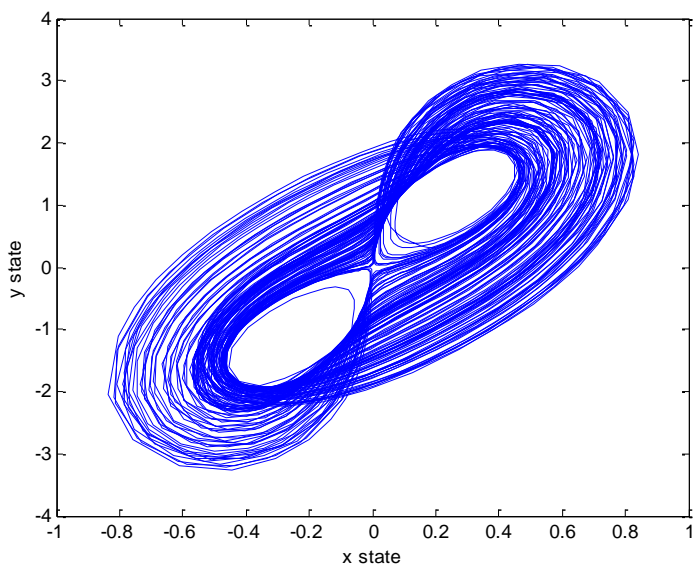

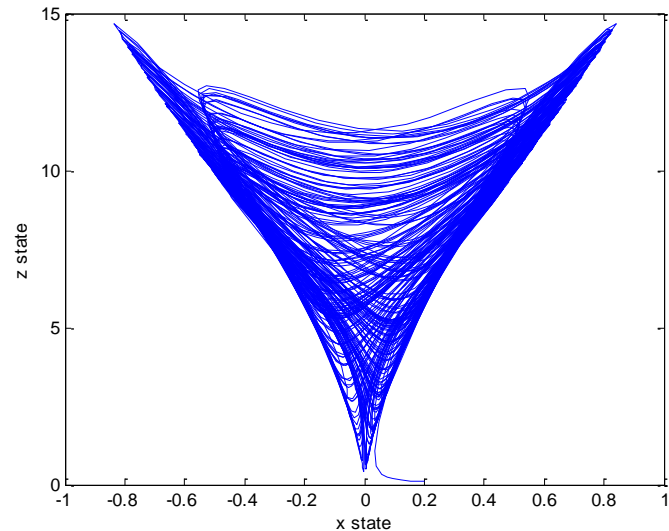
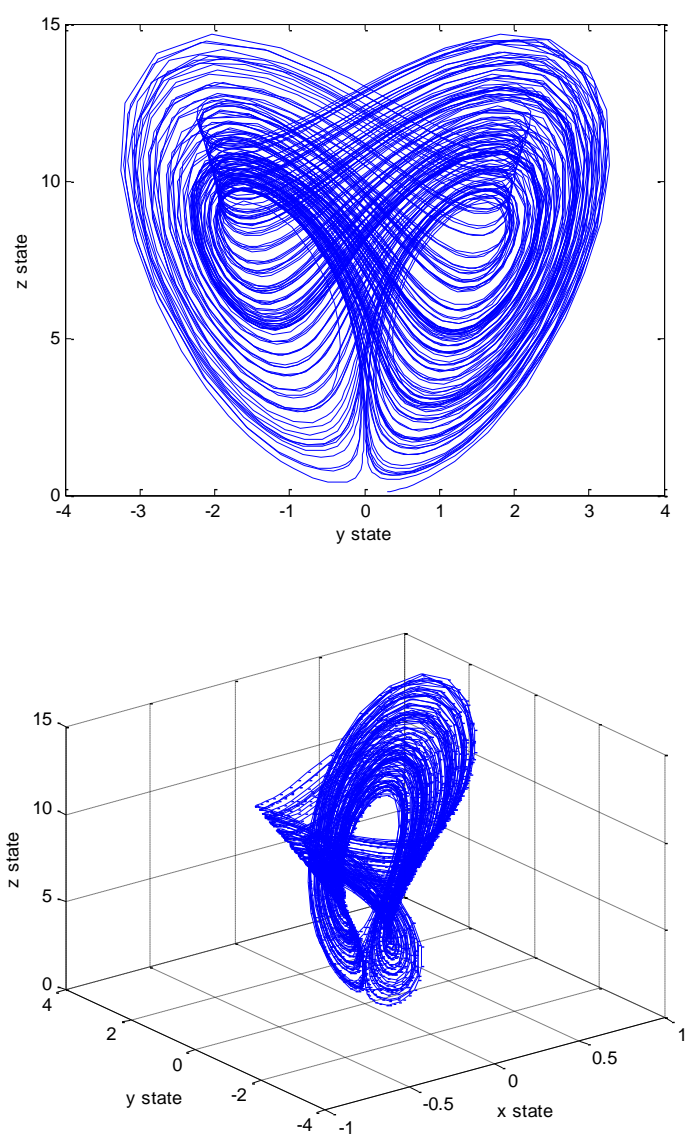

Fig. 4 Phase portraits of the 3D chaotic attractors (7) in (a) the $x y$ space, (b) the $x z$ space, (c) the $y z$ space, (d) the $x y z$ space. 


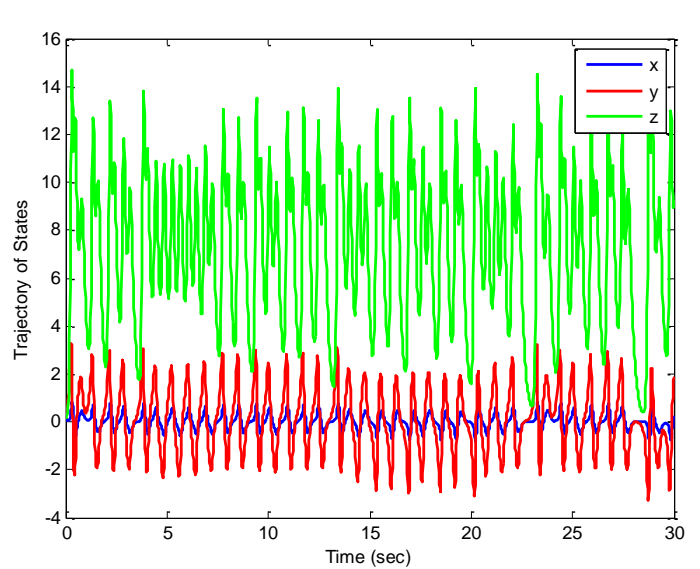

Fig. 5 State trajectory of the $3 \mathrm{D}$ chaotic attractors $(7)$

\section{SYNCHRONIZATION BETWEEN TWO NEW 3D CHAOTIC SYSTEM}

In this section, the BELBIC is applied to synchronize between two new 3D chaotic systems. Suppose the drive system takes the following from

$$
\begin{aligned}
& \dot{x}_{1}=-a x_{1}+f y_{1} z_{1} \\
& \dot{y}_{1}=c y_{1}-d x_{1} z_{1} \\
& \dot{z}_{1}=-b z_{1}+h y_{1}^{2}
\end{aligned}
$$

And the response system is given as follows

$$
\begin{aligned}
& \dot{x}_{2}=-a x_{2}+f y_{2} z_{2}+u_{1}(t) \\
& \dot{y}_{2}=c y_{2}-d x_{2} z_{2}+u_{2}(t) \\
& \dot{z}_{2}=-b z_{2}+h y_{2}^{2}+u_{3}(t)
\end{aligned}
$$

Where $u_{1}(t), u_{2}(t)$ and $u_{3}(t)$ are control functions to be determined for achieving synchronization between the two systems (8) and (9). Define state errors between system (8) and (9) as follows

$$
\begin{aligned}
& e_{x}=x_{2}-x_{1} \\
& e_{y}=y_{2}-y_{1} \\
& e_{z}=z_{2}-z_{1}
\end{aligned}
$$

We obtain the following error dynamical system by subtracting the drive system (8) from the response system (9).

$$
\begin{aligned}
& \dot{e}_{x}=-a e_{x}+f\left(y_{2} z_{2}-y_{1} z_{1}\right)+u_{1}(t) \\
& \dot{e}_{y}=c e_{y}-d\left(x_{2} z_{2}-x_{1} z_{1}\right)+u_{2}(t) \\
& \dot{e}_{z}=-b e_{z}+h\left(y_{2}^{2}-y_{1}^{2}\right)+u_{3}(t)
\end{aligned}
$$

Thus, the errors system (11) to be controlled with control inputs $u_{1}(t), u_{2}(t)$ and $u_{3}(t)$ as functions of error states $e_{x}, e_{y}$ and $e_{z}$. When system (11) is stabilized by control inputs $u_{1}(t), u_{2}(t)$ and $u_{3}(t), e_{x}, e_{y}$ and $e_{z}$ will converage to zeroes as time $t$ tends to infinity. Which implies that system (8) and (9) are synchronized.

To achieve this purpose, Input sensory of BELBIC is chosen as (12).

$$
\left\{\begin{array}{l}
s_{1}=e_{x} \\
s_{2}=e_{y} \\
s_{3}=e_{z}
\end{array}\right.
$$

The reward function's parameters for the BELBIC controller are as follows.

$$
\left\{\begin{array}{l}
\operatorname{rew}_{1}=k_{1} e_{x}+k_{2} \\
\operatorname{rew}_{2}=k_{3} e_{y}+k_{4} \\
\operatorname{rew}_{3}=k_{5} e_{z}+k_{6}
\end{array}\right.
$$

\section{OPTIMIZATION CONTROLLER}

The Genetic Algorithm [24,25], Cuckoo Optimization Algorithm [26], Particle Swarm Optimization Algorithm [27] and Imperialist Competitive Algorithm [28] are used to search the optimal parameter $(k)$ in order to guarantee the stability of systems by ensuring negativity of the Lyapunov function and having a suitable time response. The reward signals in the equation (13) are optimized by the Cost Function in the equation 14.

$$
f\left(e_{1}, e_{2}, \cdots, e_{n}\right)=\frac{1}{n} \sqrt{\sum_{i=1}^{n} e_{i}^{2}}
$$

Table 1. Genetic Algorithm Parameters

\begin{tabular}{|c|c|}
\hline Parameters & Values \\
\hline Size population & 80 \\
\hline Maximum of generation & 30 \\
\hline Prob.crossover & 0.75 \\
\hline Prob.mutation & 0.001 \\
\hline$k$ Search interval & {$[110]$} \\
\hline
\end{tabular}

Table 2. Cuckoo Optimization Algorithm Parameters

\begin{tabular}{|c|c|}
\hline Parameters & Values \\
\hline Size clusters & 2 \\
\hline Maximum number of cuckoo & 80 \\
\hline Size initial population & 5 \\
\hline Maximum iterations of cuckoo & 30 \\
\hline$k$ Search interval & {$[110]$} \\
\hline
\end{tabular}

Table 3. Particle Swarm Optimization Algorithm Parameters.

\begin{tabular}{|c|c|}
\hline Parameters & Values \\
\hline Size population & 80 \\
\hline Maximum iterations & 30 \\
\hline $\begin{array}{c}\text { Initial and Final value of the } \\
\text { global best acceleration factor }\end{array}$ & 2 and 2 \\
\hline Initial and Final value of the inertia factor & 1 and 0.99 \\
\hline$k$ Search interval & {$[110]$} \\
\hline
\end{tabular}

Table 4. Imperialist Competitive Algorithm Parameters

\begin{tabular}{|c|c|}
\hline Parameters & Values \\
\hline Number of Initial Countries & 80 \\
\hline Number of Decades & 30 \\
\hline Number of Initial Imperialists & 8 \\
\hline Revolution Rate & 0.3 \\
\hline$k$ Search interval & {$[110]$} \\
\hline
\end{tabular}




\section{NUMERICAL SIMULATION}

This section presents numerical simulations synchronization of between two new 3D chaotic systems. The initial values of the drive and response systems are $x_{1}(0)=1, y_{1}(0)=-1, z_{1}(0)=1 \quad$ and $\quad x_{2}(0)=$ $3, y_{2}(0)=-3, z_{2}(0)=3$ respectively. The optimal parameters of reward signals using genetic algorithm, cuckoo optimization algorithm, particle swarm optimization algorithm and imperialist competitive algorithm are listed in table. 5 .

Table 5. Optimal Parameters of Reward Signals.

\begin{tabular}{|c|c|c|c|c|c|c|c|c|}
\cline { 2 - 10 } \multicolumn{1}{c|}{} & $k_{1}$ & $k_{2}$ & $k_{3}$ & $k_{4}$ & $k_{5}$ & $k_{6}$ & $\alpha$ & $\beta$ \\
\hline GA & 5 & 9.24 & 5.93 & 1.76 & 6.32 & 3.39 & 9.63 & 6.1 \\
\hline PSO & 4.39 & 7.96 & 5.51 & 5.30 & 7.68 & 4.51 & 3.69 & 5.19 \\
\hline COA & 1 & 1 & 3.38 & 1 & 10 & 5.66 & 10 & 7.61 \\
\hline ICA & 3.1 & 5.79 & 9.82 & 1.10 & 8.95 & 4.71 & 4.05 & 5.25 \\
\hline
\end{tabular}

The time response of $x, y, z$ states for drive system (8) and the response system (9) via BELBIC shown in order Fig.6 until Fig.9. Synchronization errors $\left(e_{x}, e_{y}, e_{z}\right)$ in the new 3D chaotic systems shown in order Fig.10 until Fig.12. The time response of the control inputs $\left(u_{1}, u_{2}, u_{3}\right)$ for the synchronization new 3D chaotic systems shown in order Fig.13 until Fig.15.
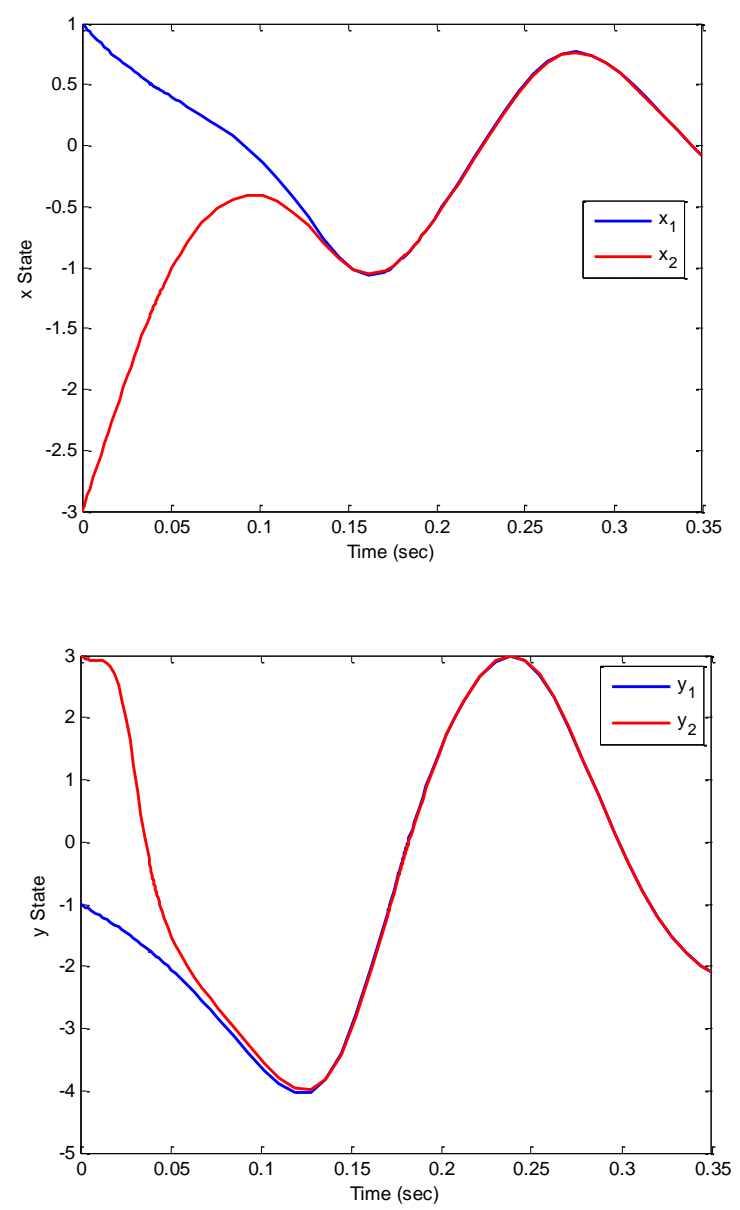

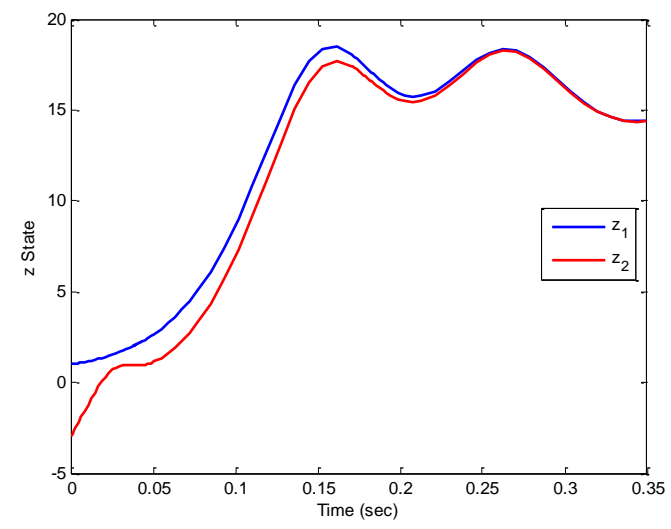

Fig. 6 The time response of signals $(x, y, z)$ for drive system (8) and response system (9) optimized by GA.
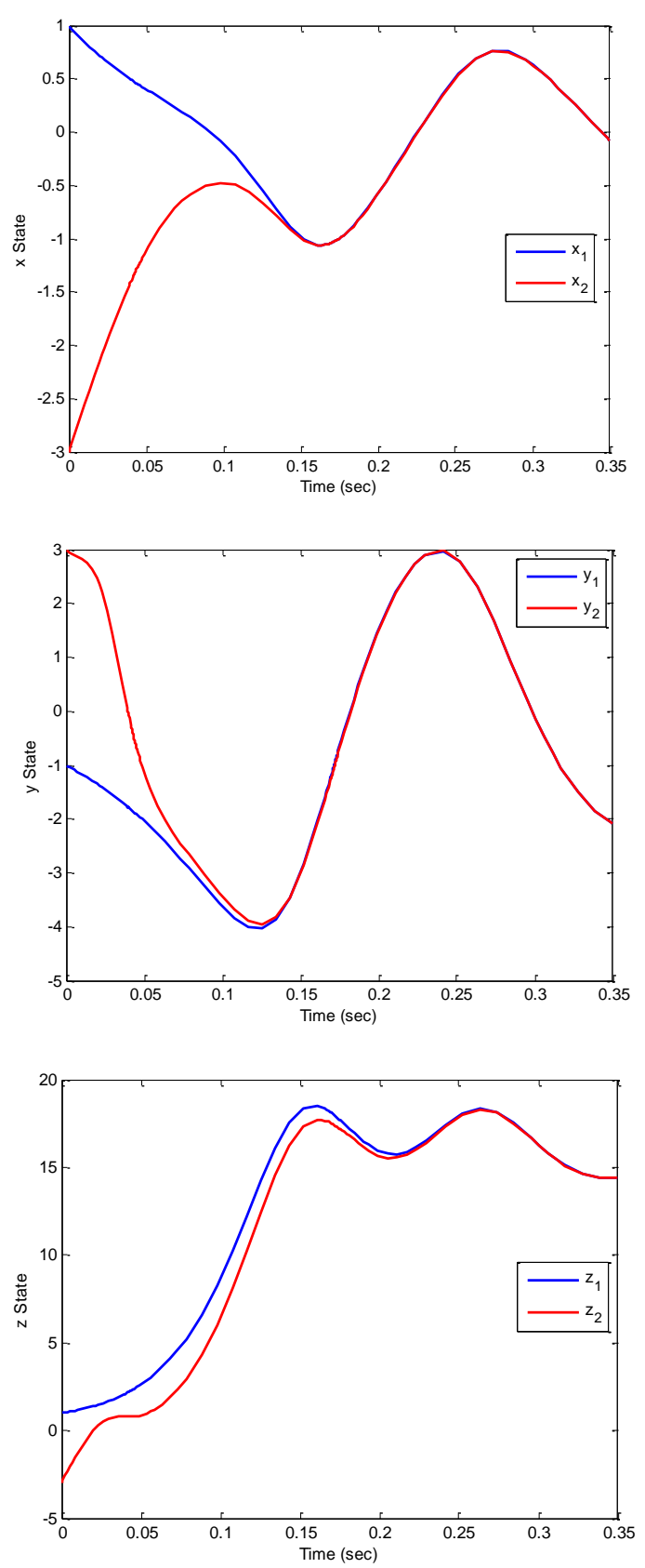

Fig. 7 The time response of signals $(x, y, z)$ for drive system $(8)$ and response system (9) optimized by PSO. 

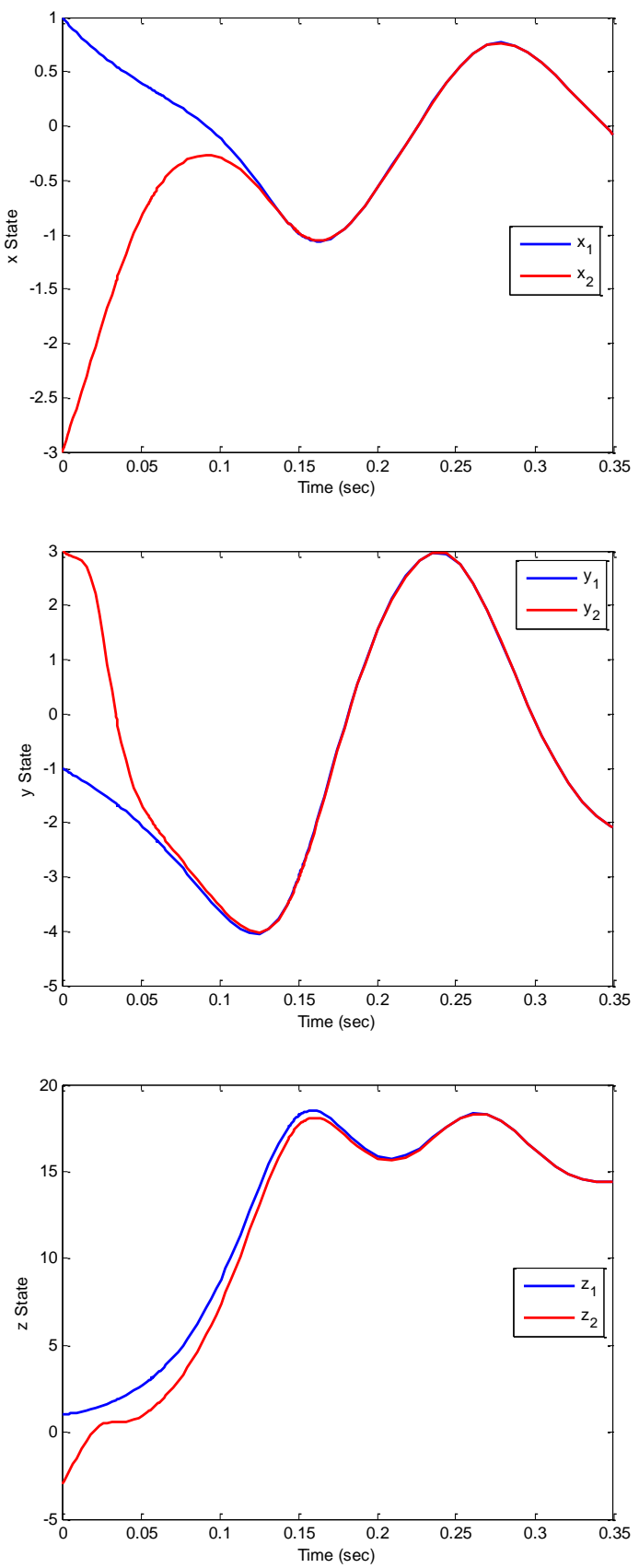

Fig. 8 The time response of signals $(x, y, z)$ for drive system (8) and response system (9) optimized by COA.

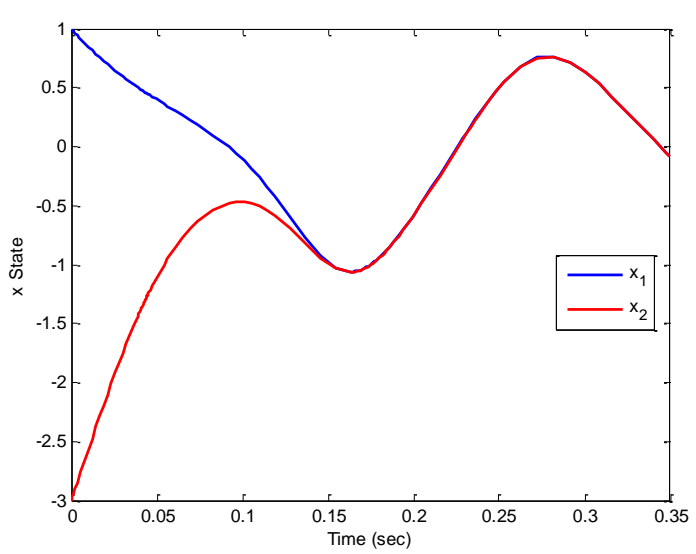

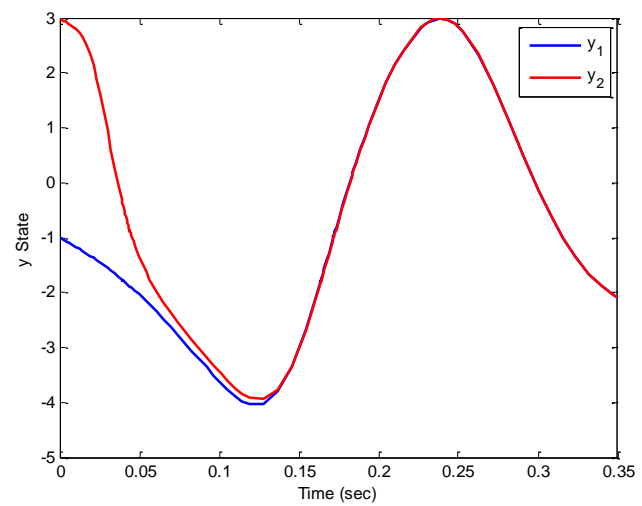

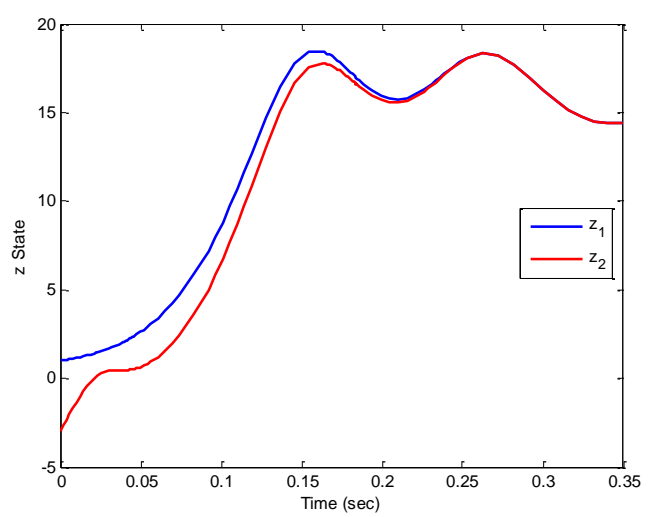

Fig.9 The time response of signals $(x, y, z)$ for drive system (8) and response system (9) optimized by ICA.

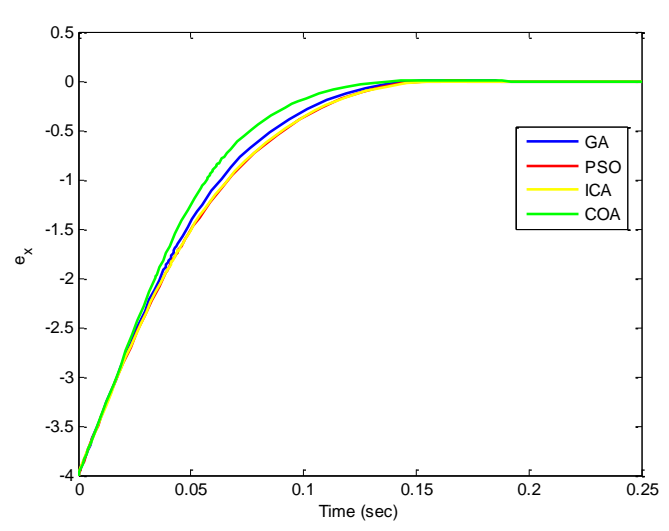

Fig.10 Synchronization error $\left(e_{x}\right)$ in drive system (8) and response system (9).

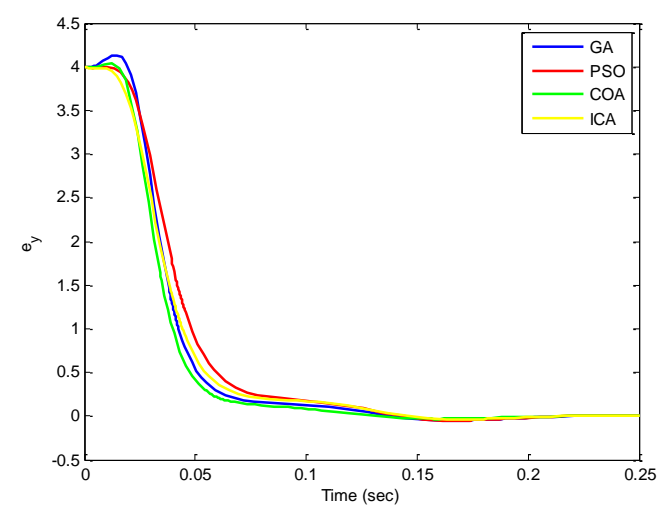

Fig.11 Synchronization error $\left(e_{y}\right)$ in drive system (8) and response system (9). 


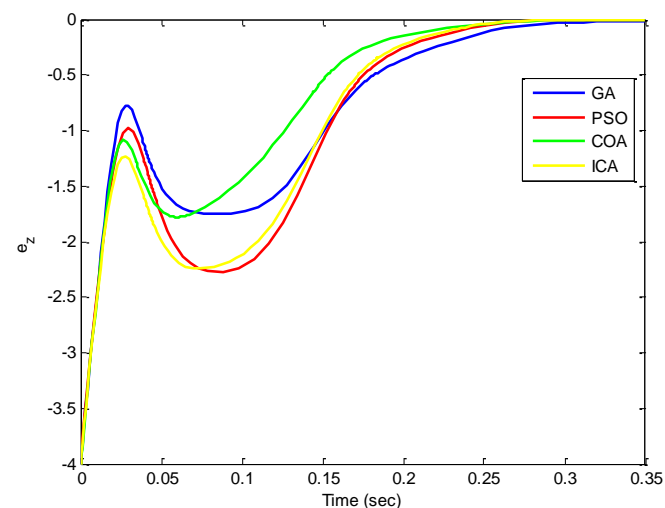

Fig. 12 Synchronization error $\left(e_{z}\right)$ in drive system (8) and response system (9).

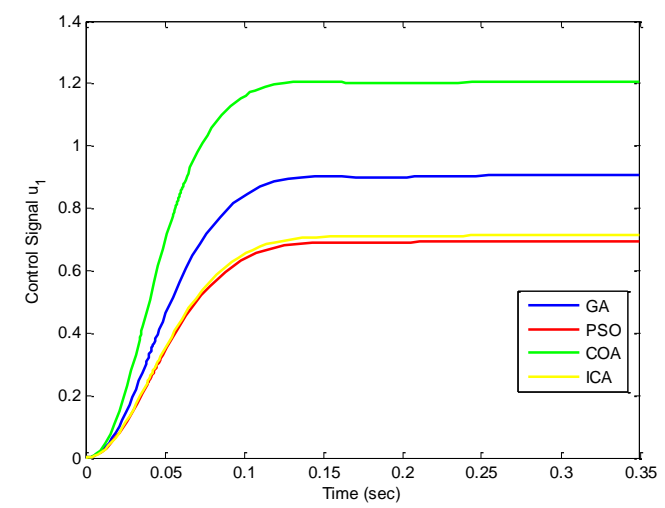

Fig. 13 The time response of the control input $\left(u_{1}\right)$ in drive system (8) and response system (9).

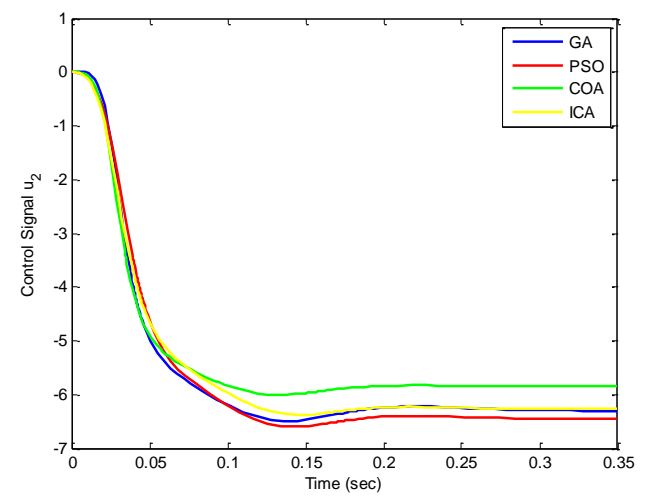

Fig. 14 The time response of the control input $\left(u_{2}\right)$ in drive system (8) and response system (9).

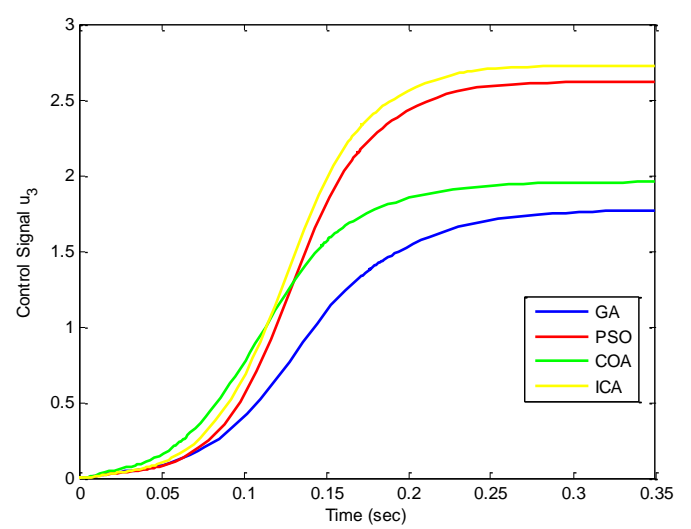

Fig. 15 The time response of the control input $\left(u_{3}\right)$ in drive system (8) and response system (9).

\section{CONCLUSION}

In this work, Chaos synchronization have been discussed. Many methods synchronized chaotic systems but many above-mentioned methods can only applied some given chaotic system, some methods will produce the singularity problem in synchronizing the chaotic system and most of the methods in the literatures need more than one variable information of the master system. In order to achieve a proper synchronization between two new 3D chaotic systems, an intelligent controller based on brain emotional learning (BELBIC) was utilized. The BELBIC consists of reward signal which accept positive values. Improper selection of the parameters causes an improper behavior which may cause serious problems such as instability of system. Eevolutionary Algorithms were well known optimization method. Genetic Algorithm, Cuckoo Optimization Algorithm, Particle Swarm Optimization Algorithm and Imperialist Competitive Algorithm optimized the BELBIC. For this reason these algorithms minimized the cost function to find minimum current value for it. On the other hand cost function found minimum value to minimize least square errors. Finally, numerical simulation was given to verify the effectiveness of the proposed synchronization scheme.

\section{REFERENCES}

[1] L.M. Pecora, T.L. Carroll, "Synchronization in chaotic systems", Phys. Rev. Lett. 64 (1990) 821-824.

[2] Hamed Kebriaei, M. Javad Yazdanpanah, Robust adaptive synchronization of different uncertain chaotic systems subject to input nonlinearity, Commun Nonlinear Sci Numer Simulat 15 (2010) 430-441.

[3] V. Sundarapandian , S. Sivaperumal, Global Chaos Synchronization of the Hyperchaotic Qi Systems by Sliding Mode Control, International Journal on Computer Science and Engineering (IJCSE), Vol. 3 No. 6 June 2011.

[4] Li-Xin Yang, Yan-Dong Chu, Jian-Gang Zhang, XianFeng Li, Ying-Xiang Chang, Chaos synchronization in autonomous chaotic system via hybrid feedback control, Chaos, Solitons and Fractals 41 (2009) 214-223.

[5] Xiaohui $\mathrm{Xu}$, Generalized function projective synchronization of chaotic systems for secure communication, Journal on Advances in Signal Processing 2011, 2011:14.

[6] Ranchao $\mathrm{Wu}$, Junlian Liu, Isochronal function projective synchronization between chaotic and time-delayed chaotic systems, Advances in Difference Equations 2012, 2012:37.

[7] V. Sundarapandian, R. Karthikeyan, Global Chaos Synchronization of Hyperchaotic Lorenz and Hyperchaotic Chen Systems by Adaptive Control, International Journal on Computer Science and Engineering (IJCSE), Vol. 3 No. 6 June 2011.

[8] M. Shahiri, R. Ghaderi, A. Ranjbar N, S.H. Hosseinnia, S. Momani, Chaotic fractional-order Coullet system: Synchronization and control approach, Commun Nonlinear Sci Numer Simulat 15 (2010) 665-674.

[9] Chih-Min Lin, Ya-Fu Peng, Ming-Hung Lin, CMAC-based adaptive backstepping synchronization of uncertain chaotic systems, Chaos, Solitons and Fractals 42 (2009) 981-988.

[10] A.R.Sahab, M.Taleb Ziabari, Adaptive Generalization Backstepping Method to Synchronize T-System, Recent 
Advances in Computers, Communications, Applied Social Science and Mathematics, ISBN: 978-1-61804-030-5.

[11] Lucas C, Shahmirzadi D, and Sheikholeslami N, "Introducing BELBIC: Brain emotional learning based intelligent control”, Int. J. Intell. Automat. Soft Comput. 2004; 10(1): 11-22.

[12] Tole Sutikno, Mochammad Facta, G.R. Arab Markadeh, "Editorial Progress in Artificial Intelligence Techniques: from Brain to Emotion", TELKOMNIKA, Vol.9, No.2, August 2011, pp. 201-202.

[13] ALI REZA MEHRABIAN, CARO LUCAS, "INTELLIGENT ADAPTIVE CONTROL OF NONLINEAR SYSTEMS BASED ON EMOTIONAL LEARNING APPROACH", International Journal on Artificial Intelligence Tools, Vol. 16, No. 1 (2007) 69-84.

[14] Amir Mehdi Yazdani, Somaiyeh Mahmoudzadeh, "Emotional Learning as a Cognitive Approach for High Performance Control of Permanent Magnet Stepper Motor", Int. J. Comp. Tech. Appl., Vol 2 (4), 1008-1015.

[15] Rasoul Mohammadi Milasi, Mohammad Reza Jamali, and Caro Lucas, "Intelligent Washing Machine: A Bioinspired and Multi-objective Approach", International Journal of Control, Automation, and Systems, vol. 5, no. 4, pp. 436443, August 2007.

[16] Hossein Rouhani, Arash Sadeghzadeh, Caro Lucas and Babak Nadjar Araabi, "Emotional learning based intelligent speed and position control applied to neurofuzzy model of switched reluctance motor", Control and Cybernetics vol. 36 (2007) No. 1.

[17] Mohammad Reza Jamali, Arash Arami, Babak Hosseini, Behzad Moshiri and Caro Lucas, "REAL TIME EMOTIONAL CONTROL FOR ANTI-SWING AND POSITIONING CONTROL OF SIMO OVERHEAD TRAVELING CRANE", International Journal of Innovative Computing, Information and Control, Volume 4, Number 9, September 2008 pp. 2333-2344.

[18] Hossein Rouhani, Mahdi Jalili, Babak N. Araabi, Wolfgang Eppler, Caro Lucas, "Brain emotional learning based intelligent controller applied to neurofuzzy model of micro-heat exchanger", Expert Systems with Applications 32 (2007) 911-918.

[19] Ali Reza Mehrabian, and Caro Lucas, "Emotional Learning based Intelligent Robust Adaptive Controller for Stable Uncertain Nonlinear Systems", INTERNATIONAL JOURNAL OF COMPUTATIONAL INTELLIGENCE VOLUME 2 NUMBER 42005 ISSN 1304-4508.

[20] Ali Reza Mehrabian, Caro Lucas, Jafar Roshanian, "Aerospace launch vehicle control: an intelligent adaptive approach", Aerospace Science and Technology 10 (2006) $149-155$.

[21] Saeed Jafarzadeh, Rooholah Mirheidari, Mohammad Reza Jahed Motlagh, Mojtaba Barkhordari, "Designing PID and BELBIC Controllers in Path Tracking Problem", Int. J. of Computers, Communications \& Control, ISSN 1841-9836, E-ISSN 1841-9844,Vol. III (2008), Suppl. issue: Proceedings of ICCCC 2008, pp. 343-348.

[22] Saeed Jafarzadeh, Rooholah Mirheidari, Mohammad Reza Jahed Motlagh, Mojtaba Barkhordari, "Intelligent Autopilot Control Design for a 2-DOF Helicopter Model", Int. J. of Computers, Communications \& Control, ISSN 1841-9836, E-ISSN 1841-9844, Vol. III (2008), Suppl. issue: Proceedings of ICCCC 2008, pp. 337-342.

[23] Chunlai Li, Hongmin Li, Yaonan Tong, "Analysis of a novel three-dimensional chaotic system ", article in press, Optik-Int. J. Light Electron Opt. (2012), http://dx.doi.org/10.1016/j.ijleo.2012.04.005.
[24] Ahmed BELHANI, Khaled BELARBI and Fateh MEHAZEM. DESIGN OF MULTIVARIABLE BACKSTEPPING CONTROLLER USING GENETIC ALGORITHM. ACSE 05 Conference, 19-21 December 2005, CICC, Cairo, Egypt.

[25] Michalewicz, Z. Genetic Algorithm + Data Structures = Evolution Programs, $2^{\text {nd }}$ Edition, Springler Verlag 1994.

[26] Ramin Rajabioun, Cuckoo Optimization Algorithm, Applied Soft Computing 11 (2011) 5508-5518.

[27] V. Rashtchi, H. Shayeghi, M. Mahdavi, A. Kimiyaghalam, E. Rahimpour, Using an Improved PSO Algorithm for Parameter Identification of Transformer Detailed Model, International Journal of Electrical Power and Energy Systems Engineering 1;3 @ $)$ www.waset.org Summer 2008.

[28] Esmaeil Atashpaz Gargari \& Caro Lucas, Imperialist Competitive Algorithm: An Algorithm for Optimization Inspired by Imperialistic Competition , 2007 IEEE Congress on Evolutionary Computation (CEC 2007) . pp 4661 - 4667.

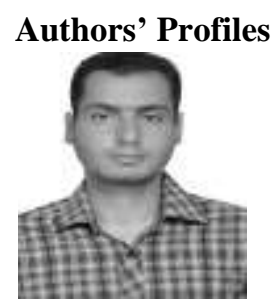

${ }^{1}$ Masoud Taleb Ziabari. Received the $\mathrm{BSc}$ in computer hardware from Islamic Azad University, Yazd, Iran in 2005. He received the MSc degree in mechatronic in Islamic Azad University Qazvin Branch, Qazvin, Iran.

His research interests include nonlinear control and intelligent systems.

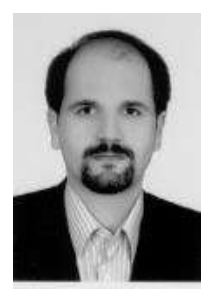

${ }^{2}$ Ali Reza Sahab. Received the B.S. in control engineering from KNT the University of Technology, Tehran, Iran in 2001 and the M.S. and $\mathrm{Ph} . \mathrm{D}$. degrees in control engineering from Shahrood University of Technology, Shahrood, Iran in 2003 and 2009 respectively.

$\mathrm{He}$ is a staff member of Electrical Group, Engineering Faculty of Islamic Azad University, Lahijan Branch. His research interests include nonlinear control and intelligent systems.

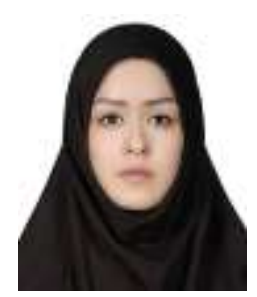

${ }^{3}$ Seyedeh Negin Seyed Fakhari. Received the BSc degree in 2007 from Lahijan University, and the Msc degree in computer engineering from Qazvin University in 2010. Her research interests include image and video processing, artificial intelligent, fuzzy logic, and classification.

How to cite this paper: Masoud Taleb Ziabari, Ali Reza Sahab, Seyedeh Negin Seyed Fakhari,"Synchronization New 3D Chaotic System Using Brain Emotional Learning Based Intelligent Controller", International Journal of Information Technology and Computer Science(IJITCS), vol.7, no.2, pp.8087, 2015. DOI: 10.5815/ijitcs.2015.02.10 